\title{
BMJ Randomised controlled trial of an Open education and support package for stroke patients and their carers
}

\author{
Sally Eames, ${ }^{1}$ Tammy Hoffmann, ${ }^{2}$ Linda Worrall, ${ }^{3}$ Stephen Read, ${ }^{4}$ Andrew Wong ${ }^{4}$
}

To cite: Eames $\mathrm{S}$,

Hoffmann $\mathrm{T}$, Worrall L, et al. Randomised controlled trial of an education and support package for stroke patients and their carers. BMJ Open 2013:3:e002538

doi:10.1136/bmjopen-2012002538

- Prepublication history and additional material for this paper are available online. To view these files please visit the journal online (http://dx.doi.org/10.1136/ bmjopen-2012-002538).

Received 29 December 2012 Revised 16 March 2013 Accepted 25 March 2013

This final article is available for use under the terms of the Creative Commons Attribution Non-Commercial 2.0 Licence; see http://bmjopen.bmj.com

For numbered affiliations see end of article.

Correspondence to

Dr Sally Eames;

sally_eames@health.qld.gov.

au

\section{ABSTRACT}

Objective: Tailoring stroke information and providing reinforcement opportunities are two strategies proposed to enhance the effectiveness of education. This study aimed to evaluate the effects of an education package which utilised both strategies on the knowledge, health and psychosocial outcomes of stroke patients and carers.

Design: Multisite, randomised trial comparing usual care with an education and support package.

Setting: Two acute stroke units.

Participants: Patients and their carers $(\mathrm{N}=138)$ were randomised (control $n=67$, intervention $n=71$ ) of which data for 119 participants (control $n=59$, intervention $\mathrm{n}=60$ ) were analysed.

Intervention: The package consisted of a computergenerated, tailored written information booklet and verbal reinforcement provided prior to, and for 3 months following, discharge.

Outcome measures: Outcome measures were administered prior to hospital discharge and at 3month follow-up by blinded assessors. The primary outcome was stroke knowledge (score range: $0-25$ ). Secondary outcomes were: self-efficacy (1-10), anxiety and depression (0-21), ratings of importance of information (1-10), feelings of being informed (1-10), satisfaction with information (1-10), caregiver burden (carers) (0-13) and quality of life (patients) (1-5). Results: Intervention group participants reported better: self-efficacy for accessing stroke information (adjusted mean difference (MD) of 1.0, 95\% $\mathrm{Cl} 0.3$ to 1.7, $p=0.004$ ); feeling informed (MD $0.9,95 \% \mathrm{Cl} 0.2$ to 1.6, $\mathrm{p}=0.008$ ); and satisfaction with medical (MD 2.0, $95 \% \mathrm{Cl} 1.1$ to 2.8, $\mathrm{p}<0.001$ ); practical (MD $1.1,95 \% \mathrm{Cl}$ 0.3 to $1.9, p=0.008$ ), services and benefits (MD 0.9, $95 \% \mathrm{Cl} 0.1$ to $1.8, \mathrm{p}=0.036$ ) and secondary prevention information (MD 1.7, $95 \% \mathrm{Cl} 0.9$ to 2.5, $\mathrm{p}<0.001$ ). There was no significant effect on other outcomes. Conclusions: Intervention group participants had improved self-efficacy for accessing stroke information and satisfaction with information, but other outcomes were not significantly affected. Evaluation of a more intensive intervention in a trial with a larger sample size is required to establish the value of an educational intervention that uses tailoring and reinforcement strategies.

ACTRN12608000469314

\section{ARTICLE SUMMARY}

Article focus

- Patient and carer education is a crucial component of poststroke care but little is known about the most effective way of providing it.

- Tailoring stroke information and providing opportunities for reinforcement have been suggested as useful strategies.

- This study aimed to evaluate the effects of an education package which used both of these strategies on the knowledge, health, psychosocial and satisfaction outcomes of stroke patients and carers.

Key messages

- The education and support package included a computer-generated, tailored written information booklet and verbal reinforcement which started in the hospital and continued during the 3 months following discharge.

- The package improved stroke self-efficacy for accessing stroke information and satisfaction with information received.

- The effects of tailored messages and verbal reinforcement on other outcomes, such as knowledge, mood, quality of life/caregiver burden, remain unknown.

Strengths and limitations of this study

- The intervention evaluated in this study was theoretically informed, developed with patient and carer input and expanded on a previous trial. The inclusion of both patients and carers enhances the applicability to clinicians working in this area as patients are often seen with their carers or a family member.

- Results may not be generalisable to all patients with stroke. The sample size was small and the study likely to be underpowered. Some of the outcome measures lack formal evaluation of psychometric properties.

\section{INTRODUCTION}

Stroke information provision is a crucial component of care for patients and carers ${ }^{1-3}$; however, their information needs are often poorly met. ${ }^{4-8}$ Information needs vary 
between individuals ${ }^{9}$ and tailoring of information to individual patient and/or carer needs is required. ${ }^{10-13}$

Three tailored written information interventions for patients with stroke have been evaluated in randomised trials. ${ }^{14-16}$ In an evaluation of booklets that contained information previously presented verbally, there were no significant differences in physical or social functioning between groups. ${ }^{14}$ Evaluation of individualised information booklets that were verbally reinforced in one session found significantly better stroke knowledge for intervention group patients, but no other between-group differences. ${ }^{15}$ In a trial which compared a computergenerated tailored written information booklet ('What you need to know about stroke') with generic nontailored stroke information, intervention group patients had significantly better satisfaction with information received and their information needs were better met, but no other significant improvements compared with the control group. ${ }^{16}$ These studies suggest that while there may be some benefits associated with tailored written information, refinement of tailored stroke educational interventions and further research are required.

A possible mechanism for enhancing the effectiveness of stroke information interventions is suggested in a Cochrane review, in which 'active' interventions (which actively included patients and carers and provided the opportunity to clarify and reinforce information) were found to be more effective at improving patient anxiety and depression than passive ones. ${ }^{17}$ Furthermore, because patients and carers continue to have information needs after leaving hospital, ${ }^{4} 818$ continued access to information after discharge is recommended. ${ }^{1}$

In the current study, an education and support package for patients and carers that expanded upon the previously evaluated 'What you need to know about stroke' tailored booklet and provided opportunities for clarification and reinforcement of information both prior to, and following, discharge was developed. Research into patients' and carers' information needs and format preferences ${ }^{19}$ was also used to inform the intervention design, as was the Health Belief Model $^{20}$ and adult learning principles. The Health Belief Model has previously been used in the area of stroke as a basis to explore patient beliefs regarding risk-related behaviour change. ${ }^{21}$ The model assumes that in order for behaviour change to occur, a person must believe: that they are at risk of a particular illness (perceived susceptibility); that the consequence of that illness is serious (perceived severity); that making the behaviour change can produce a positive outcome ( perceived benefit) and that the perceived benefit of behaviour change outweighs any perceived barriers to behaviour change. ${ }^{20}$ Another component of the model is the person's selfefficacy (confidence in their ability) to perform a behaviour. ${ }^{20}$ As the intervention was targeted at adults, the principles of adult learning were also incorporated in the education package. ${ }^{22}$ These principles include consideration of a person's: need to know, self-concept, prior experiences, readiness to learn, orientation to learning and motivation to learn. ${ }^{22}$

The research question addressed by this study was 'What are the effects of an education and support package on the knowledge, health, psychosocial and satisfaction outcomes of stroke patients and carers?' The primary aim of this study was to evaluate the effect of this education package on the knowledge of stroke patients and carers, with a secondary aim of evaluating its effect on participants' self-efficacy, mood, feelings of being informed and the importance of information, satisfaction and patient quality of life/carer burden.

\section{METHODS}

\section{Participants and study design}

Eligible patients consecutively identified as nearing discharge from the acute stroke unit of two public, tertiary hospitals in Brisbane, Australia and their carers were invited to participate in this randomised trial. Eligibility criteria included: (1) having, or being a carer for someone with, a current diagnosis of stroke (first or subsequent) or transient ischaemic attack; (2) not living in residential care prior to admission to hospital, or having residential care as the planned discharge destination; (3) contactable by telephone and (4) adequate English, cognition and communication, vision and hearing to participate in an interview and complete the questionnaire. Members of the treating interdisciplinary team assisted in identifying eligible patients and available and eligible carers. For example, the treating speech pathologist advised on the patient's communication ability, and the treating doctor or occupational therapist advised on the patient's cognitive ability. If the patient was ineligible, available carers were still approached.

\section{Procedure}

The lead author obtained written informed consent and completed the initial interviews. Concealed random allocation was achieved via sequentially numbered envelopes containing computer-generated random numbers prepared by a person not involved in the study. Paired patient and carer dyads were allocated to the same group. Participants then received standard care (control group) or standard care and the intervention (intervention group) until 3 months following discharge.

Outcome measures were administered face-to-face prior to acute stroke unit discharge (mean 12.8, SD 9.3 days since stroke). They were re-administered via telephone 3 months after discharge (mean 112.1, SD 14.1 days since stroke) by a different researcher who was blind to group allocation. Once completed, this assessor opened a sealed section of the form to determine group allocation and asked intervention group participants additional questions regarding the intervention. A comparison of telephone and face-to-face administration of these measures found no significant differences between the two methods. ${ }^{23}$ 
Demographic and clinical characteristics were collected at baseline from participant interviews and from the patient's medical chart. The Rapid Estimate of Adult Literacy in Medicine (REALM) ${ }^{24}$ was also administered at baseline as an estimate of the participant's reading ability. REALM is a reading recognition test with good test-retest reliability and concurrent validity with standardised reading tests. ${ }^{24}$ Ethical clearance was obtained from relevant hospital and university ethics committees and the trial was registered with the Australian and New Zealand Clinical Trials Registry (ACTR Number: ACTRN12608000469314).

\section{Intervention}

Control group participants received standard stroke unit care (medical, nursing and allied-health assessment and treatment, which included the provision of unstructured informal verbal education and advice from various members of the treating team). Structured stroke education or support groups were not offered at either site during the time of this study, and nor were written materials routinely provided. Participants in the intervention group received the education and support package in addition to standard care.

The design of the education and support package was informed by recommendations from the literature, ${ }^{25}$ and previous research by the author team which explored current practice gaps, ${ }^{25}$ patient and carer preferences for receiving information ${ }^{19}$ and potential barriers to information provision. ${ }^{26}$ The health professional providing the package was the lead author, who is an occupational therapist with clinical experience in stroke rehabilitation; however, the intervention was designed so that it could be provided by any health professional who has knowledge and experience in stroke management.

The package consisted of: a previously evaluated and described computer-generated, tailored written information booklet (http://www.uq.edu.au/tru/strokebook) ${ }^{16} 27$; verbal reinforcement of information up to three times predischarge; telephone contact up to three times postdischarge and a telephone number that participants could call with questions. Participants could tailor the written information by choosing topics from a list of 34 topics and the level of information detail (detailed or brief) ${ }^{27}$ (please see online supplementary appendix A for this checklist) and the verbal sessions by nominating the topics for discussion. Intervention group participants received the written information and face-to-face sessions prior to the discharge interview (please see online supplementary appendices B and $\mathrm{C}$ for the Intervention Protocol and Intervention Template). Following discharge, telephone contact with participants was provided by three health professional-initiated telephone calls at intervals of approximately 1 month, over a 3-month period (please see online supplementary appendices B and C). As the Health Belief Model $^{20}$ and adult learning principles ${ }^{22}$ were used to inform the development of the intervention, the health professional providing the intervention incorporated the following strategies where possible: assessing knowledge, exploring barriers and ways to overcome them; correcting misinformation; providing specific and personalised information about the risks and seriousness of unhealthy behaviour, and specific details of the benefits of healthy behaviour; providing reassurance and encouraging the use of support networks; using persuasion and training in breaking tasks into smaller steps and encouraging the use of stress management strategies.

The health professional providing the intervention was not a member of the interdisciplinary team at either stroke unit and approached participants independent of the standard treating team. Face-to-face sessions were conducted at the patient's bedside or in a quiet interview room nearby. In the case of participating dyads (both the patient and their carer allocated to the intervention group), participants were offered the choice of combined or separate education sessions. The information needs checklist, intervention protocol and the intervention tracking template are provided as online supplementary materials. Further details of the intervention are available from the author on request.

\section{Outcome measures}

The primary outcome was stroke knowledge which was assessed using the 25-item Knowledge of Stroke Questionnaire, ${ }^{16}$ which has a true/false/do not know response format with good test-retest reliability, ${ }^{28}$ with higher scores indicating better stroke knowledge. Secondary outcomes were self-efficacy, anxiety and depression, quality of life (patients) and caregiver burden (carers) and ratings of: being informed; importance of information and satisfaction with information received. Owing to the lack of a suitable existing measure, the tool for assessing self-efficacy in accessing and using stroke information was developed for this study, drawing on Lorig et $a l \mathrm{~s}^{29}$ Self-efficacy to Perform Self-Management Behaviour measures for chronic disease. It consists of nine items (see table 1), each scoring self-efficacy on a 1-10 Likert scale, and using a stem statement of 'At the moment, how confident are you that you...?'

Anxiety and depression were assessed using the 14-item Hospital Anxiety and Depression Scale (HADS) ${ }^{30}$ (scores range from 0 to 21 for each anxiety and depression subscale), with higher scores indicating higher levels of anxiety or depression. The internal consistency, as indicated by Spearman's correlation, of HAD's anxiety subscale items has been reported as ranging from 0.76 to $0.41(\mathrm{p}<0.01$ for all items) and for the depression subscale, 0.60 to 0.30 (all lower than $\mathrm{p}<0.02) .{ }^{30}$ Self-reported ratings of being informed, the importance of information and satisfaction with information received were assessed using 10-point Likert scales, where $1=$ 'not at all...' and $10=$ 'extremely...'

Finally, patient-specific quality of life was assessed using the Stroke and Aphasia Quality of Life Scale-39 Generic (SAQOL-39g), which has been validated on 
Table 1 Baseline and 3-month follow-up outcome measures scores

\begin{tabular}{|c|c|c|c|c|c|c|}
\hline \multirow[b]{2}{*}{ Outcome (score range) } & \multicolumn{2}{|c|}{$\begin{array}{l}\text { Mean (SD) baseline } \\
\text { scores }\end{array}$} & \multicolumn{2}{|c|}{$\begin{array}{l}\text { Mean (SD) follow-up } \\
\text { scores }\end{array}$} & \multicolumn{2}{|l|}{ ANCOVA results } \\
\hline & $\begin{array}{l}\text { Control } \\
\text { group } \\
(n=59)\end{array}$ & $\begin{array}{l}\text { Intervention } \\
\text { group }(n=60)\end{array}$ & $\begin{array}{l}\text { Control } \\
\text { group } \\
(n=59)\end{array}$ & $\begin{array}{l}\text { Intervention } \\
\text { group }(n=60)\end{array}$ & $\begin{array}{l}\text { Between-group } \\
\text { difference } \\
\text { adjusted mean } \\
(95 \% \mathrm{Cl})\end{array}$ & p Value \\
\hline Stroke knowledge (0-25) & $17.2(3.9)$ & $17.5(3.1)$ & $18.7(3.5)$ & $19.8(3.0)$ & $0.7(-1.9$ to 0.5$)$ & 0.256 \\
\hline \multicolumn{7}{|l|}{ Self-efficacy $(1-10)$} \\
\hline Cope with stroke & $6.8(2.6)$ & $7.1(2.3)$ & $7.7(1.9)$ & $8.1(1.8)$ & $0.2(-0.5$ to 0.8$)$ & 0.600 \\
\hline Access practical help & $7.8(2.3)$ & $8.2(2.0)$ & $8.3(1.9)$ & $8.5(1.5)$ & $0.2(-0.4$ to 0.9$)$ & 0.483 \\
\hline Access emotional help & $7.8(2.4)$ & $8.0(2.1)$ & $8.1(2.0)$ & $8.0(2.1)$ & $0.0(-0.7$ to 0.9$)$ & 0.909 \\
\hline Manage stress & $7.2(2.3)$ & $7.5(2.2)$ & $7.3(2.1)$ & $7.6(1.7)$ & $0.2(-0.5$ to 0.9$)$ & 0.584 \\
\hline Access stroke information & $7.6(2.5)$ & $7.8(2.4)$ & $7.8(2.2)$ & $8.8(1.4)$ & $1.0(0.3$ to 1.7$)$ & $0.004^{*}$ \\
\hline Understand stroke information & $7.9(1.9)$ & $7.9(2.1)$ & $7.9(1.9)$ & $8.5(1.4)$ & $0.6(-0.1$ to 1.2$)$ & 0.077 \\
\hline Talk with doctor & $8.6(2.0)$ & $8.9(1.4)$ & $8.7(1.5)$ & $8.9(1.7)$ & $0.1(-0.5$ to 0.8$)$ & 0.651 \\
\hline Talk with health professionals & $8.5(1.8)$ & $8.7(1.8)$ & $8.6(1.6)$ & $8.7(1.6)$ & $0.2(-0.4$ to 0.8$)$ & 0.567 \\
\hline Prevent (another) stroke & $7.0(2.4)$ & $6.9(2.7)$ & $6.8(2.2)$ & $7.3(2.7)$ & $0.2(-0.7$ to 1.2$)$ & 0.608 \\
\hline Anxiety $(0-21)$ & $7.5(4.2)$ & $8.7(4.5)$ & $6.6(4.3)$ & $7.3(4.3)$ & $0.5(-1.1$ to 2.1$)$ & 0.559 \\
\hline Depression (0-21) & $5.0(3.4)$ & $5.4(3.8)$ & $4.3(3.5)$ & $4.9(3.7)$ & $0.6(-0.7$ to 2.0$)$ & 0.377 \\
\hline Feeling informed $(1-10)$ & $6.1(2.6)$ & $6.0(2.3)$ & $7.3(1.9)$ & $8.2(1.7)$ & $0.9(0.2$ to 1.6$)$ & $0.008^{*}$ \\
\hline Importance of information (1-10) & $9.9(0.4)$ & $9.6(1.2)$ & $9.4(1.4)$ & $9.5(1.1)$ & $0.1(-0.4$ to 0.6$)$ & 0.615 \\
\hline \multicolumn{7}{|c|}{ Satisfaction with information received $(1-10)$} \\
\hline Medical information & $6.3(2.5)$ & $6.5(2.3)$ & $6.8(2.6)$ & $8.8(1.8)$ & $2.0(1.1$ to 2.8$)$ & $<0.001^{*}$ \\
\hline Practical information & $5.9(2.7)$ & $6.2(2.7)$ & $7.4(2.5)$ & $8.5(1.9)$ & 1.1 (0.3 to 1.9$)$ & $0.008^{*}$ \\
\hline Service and benefits & $5.3(3.0)$ & $5.8(2.8)$ & $7.1(2.7)$ & $7.9(1.8)$ & $0.9(0.1$ to 1.8$)$ & $0.036^{*}$ \\
\hline Prevention information & $5.8(2.7)$ & $6.2(2.7)$ & $6.9(2.6)$ & $8.6(1.7)$ & $1.7(0.9$ to 2.5$)$ & $<0.001^{*}$ \\
\hline Quality of life (patients) (1-5) & $\begin{array}{l}(n=31) \\
3.5(0.8)\end{array}$ & $\begin{array}{l}(n=35) \\
3.6(0.9)\end{array}$ & $\begin{array}{l}(n=31) \\
4.0(0.7)\end{array}$ & $\begin{array}{l}(n=35) \\
4.0(0.7)\end{array}$ & $0.1(-0.2$ to 0.4$)$ & 0.496 \\
\hline Caregiver burden (carers) (0-13) & $\begin{array}{l}(n=28) \\
4.8(2.9)\end{array}$ & $\begin{array}{l}(n=25) \\
5.8(3.4)\end{array}$ & $\begin{array}{l}(\mathrm{n}=28) \\
6.2(3.7)\end{array}$ & $\begin{array}{l}(n=25) \\
6.5(3.4)\end{array}$ & $0.1(-2.0$ to 2.1$)$ & 0.932 \\
\hline
\end{tabular}

patients with and without aphasia. ${ }^{31}$ The 39 items, each scored on a Likert scale of 1-5, are organised into three categories: physical, psychosocial and communication. Higher category and total means indicate a better quality of life. The SAQOL-39 has acceptable test-retest reliability (intraclass correlation coefficient $=0.89-0.98$ ), internal consistency (Cronbach's $\alpha=0.74-0.94$ ) and construct validity (corrected domain-total correlations, $\mathrm{r}=0.38-0.58$; convergent, $\mathrm{r}=0.55-0.67$; discriminant, $\mathrm{r}=0.02-0.27$ validity) ${ }^{32}$ A carer-specific measure of burden was assessed using the Caregiver Strain Index, for which scores range from 0 to 13 , with higher total scores indicating a higher burden. ${ }^{33}$ It has strong internal consistency (Cronbach's $\alpha=0.86$ ), ${ }^{33}$ clinical validity and significant correlation with other caregiver burden scales. ${ }^{34}$

Finally, questions were asked of the intervention group participants to obtain feedback on the intervention. These included asking if they had read the booklet, and the usefulness of each of the four components of the intervention on a 1-10 Likert scale, where $1=$ 'not at all useful' and $10=$ 'extremely useful'.

\section{Sample size and statistical analysis}

A sample size calculation was conducted for the primary outcome of stroke knowledge based on data from previous research ${ }^{16}$ and on the expectation that a between-group difference of a mean score of 2 would be clinically significant. Assuming equality of groups preintervention, using an SD of 3.6, a power of 0.8 and a significance level of 0.05 (two-sided), a required sample size of 102 (51 in each group) was predicted. To allow for a possible attrition rate of $25 \%$, a target of 136 participants was set. Statistical analysis was conducted using STATA (V.10) and on an intention-to-treat basis. Owing to baseline differences in age between the groups, analysis of covariances were completed on follow-up scores for all outcomes. Participants included both patients and carers, with data analysed together.

\section{RESULTS}

The flow of participants through the trial is presented in figure 1. Recruitment occurred over a 13-month period between 2008 and 2009, during which time 273 patients 
Figure 1 Flow chart of participants.
Enrollment

Patients $(n=273)$ and available carers $(n=102)$ assessed for eligibility

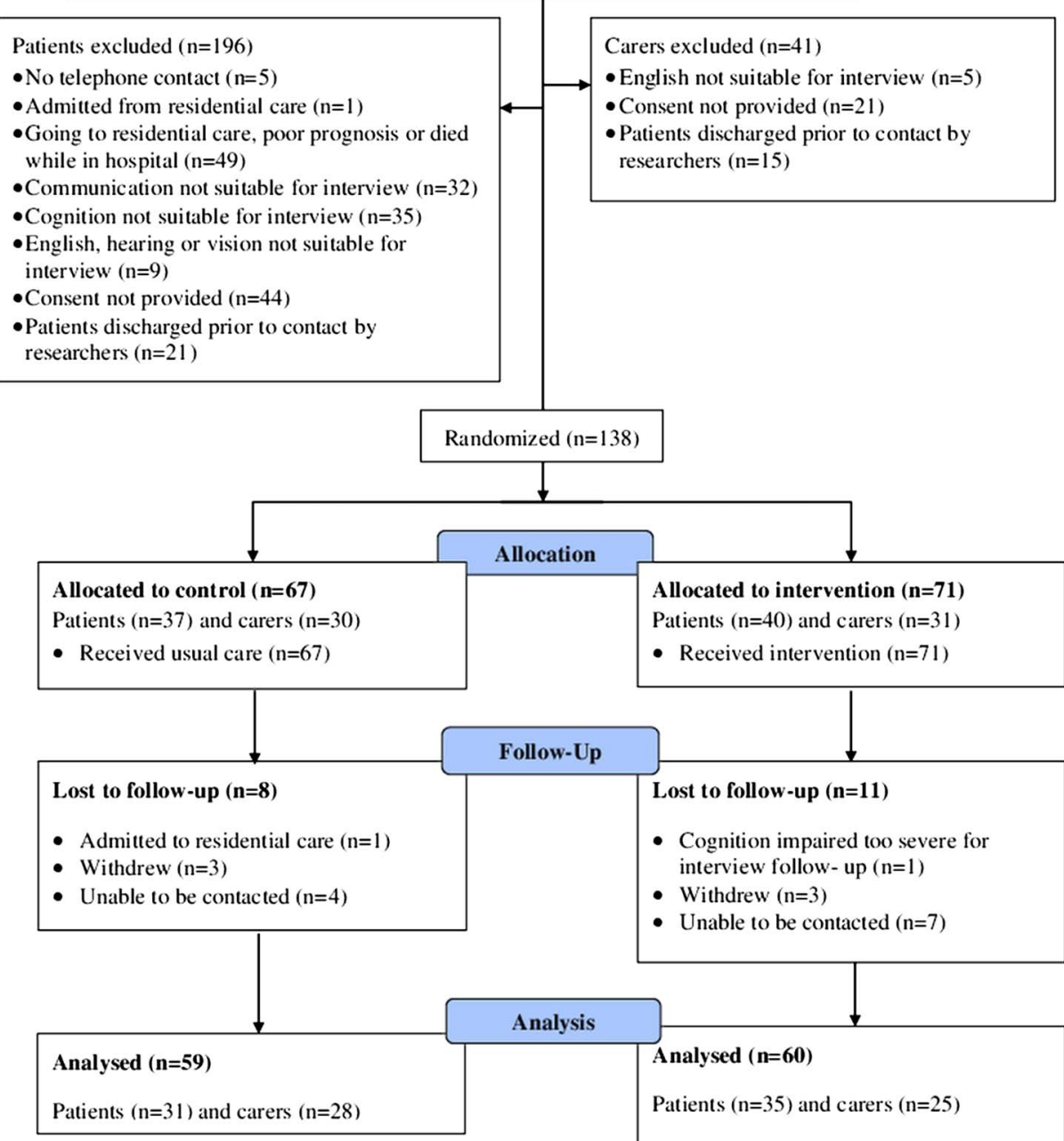

and 102 available carers were assessed for eligibility. Of the 138 participants randomised, 8 control group participants and 11 intervention group participants were lost to follow-up, resulting in an overall follow-up rate of $86 \%$. The demographic and clinical characteristics of participants are presented in table 2. Just over half of the participants $(55.5 \%)$ had their paired patient or carer also participating in the study. Baseline and follow-up outcome measure scores are presented in table 1. The participant's mean age at baseline was significantly different between the control and intervention groups (61.8 vs 55.1 years).

At the 3-month follow-up, there were no significant between-group differences for stroke knowledge. Participants in the intervention group did, however, have significantly better: self-efficacy for accessing stroke information (adjusted mean difference (MD) of 1.0, $95 \%$ CI 0.3 to $1.7, \mathrm{p}=0.004$ ); feeling informed (MD 0.9, $95 \%$ CI 0.2 to $1.6, \mathrm{p}=0.008$ ); and satisfaction with information received relating to medical (MD 2.0, 95\% CI
1.1 to $2.8, \mathrm{p}<0.001$ ); practical (MD $1.1,95 \%$ CI 0.3 to $1.9, \mathrm{p}=0.008)$, services and benefits (MD 0.9, 95\% CI 0.1 to $1.8, \mathrm{p}=0.036$ ) and secondary prevention (MD 1.7, $95 \%$ CI 0.9 to $2.5, \mathrm{p}<0.001$; see table 1$)$. There were no significant between-group differences for the other outcomes.

\section{Intervention provision and feedback}

The mean number of contacts prior to discharge was 1.3 (SD 0.6, range 1-3) and 2.5 (SD 0.9 range $0-3$ ) following discharge. The mean total minutes of contact prior to discharge was 25.5 (SD 14.9, range 2-60) and following discharge was 8.6 (SD 8.3, range 1-43). The mean length of total contact time (face-to-face and telephone) was $59.1 \mathrm{~min}$ (SD 40.0, range 9-196). Only one participant (a patient) made use of the telephone support number to contact the health professional with a question. Please see table 3 which presents the proportion of participants who reported each component of the intervention as useful and the mean usefulness rating. Fifty-five $(91.7 \%)$ 
Table 2 Demographic and clinical characteristics at baseline

\begin{tabular}{|c|c|c|}
\hline Variable & Control $(n=67)$ & Intervention $(\mathrm{n}=71)$ \\
\hline Mean age in years (SD; range) & $61.4(12.7 ; 24-86)$ & $55.2(16.7 ; 27-97)$ \\
\hline Female gender & $36(53.7)$ & $39(54.9)$ \\
\hline \multicolumn{3}{|l|}{ Living with } \\
\hline Alone & $10(14.9)$ & $13(18.3)$ \\
\hline Partner/family & $57(85.1)$ & $58(81.7)$ \\
\hline Relationship to patient* & $(n=30)$ & $(n=31)$ \\
\hline Partner & $21(70.0)$ & $20(64.5)$ \\
\hline Child & 7 (23.3) & $9(29.0)$ \\
\hline Sibling/other & $2(6.7)$ & $2(6.5)$ \\
\hline Mean years of schooling (SD; range) & $11.8(3.6 ; 2-21)$ & $12.1(3.3 ; 6-20)$ \\
\hline REALM grade equivalent $\dagger$ & $(n=62)$ & $(n=67)$ \\
\hline$\leq 3 \mathrm{rd}$ & 0 & $1(1.5 \%)$ \\
\hline 4th-6th & $3(4.8)$ & $3(4.5)$ \\
\hline 7th-8th & $19(30.6)$ & $19(28.4)$ \\
\hline$\geq 9$ th & $40(64.5)$ & $44(65.7)$ \\
\hline Patient stroke type & $(n=36) \S$ & $(n=40)$ \\
\hline Ischaemic & $31(86.1)$ & $29(72.5)$ \\
\hline Haemorrhagic & $5(13.9)$ & $10(25)$ \\
\hline TIA & 0 & $1(2.5)$ \\
\hline Patient side of stroke $\ddagger$ & $(n=36) \S$ & $(n=40)$ \\
\hline Left & 12 (33.3) & $15(37.5)$ \\
\hline Right & 21 (58.3) & $24(60.0)$ \\
\hline Bilateral & $3(8.3)$ & $1(2.5)$ \\
\hline First-time stroke $\ddagger$ & $(n=37) 31(83.8)$ & $(n=40) 27(67.5)$ \\
\hline \multicolumn{3}{|c|}{$\begin{array}{l}\text { Values are numbers (percentages) unless otherwise stated. } \\
\text { *Carer participants only. } \\
\text { †Eight patients and one carer were unable to complete REALM due to poor vision. } \\
\text { †Patient participants only. } \\
\text { §One patient's stroke type and side was missing. } \\
\text { REALM, Rapid Estimate of Adult Literacy in Medicine; TIA, transient ischaemic attack. }\end{array}$} \\
\hline
\end{tabular}

participants in the intervention group stated that they had read the written booklet. There were no differences between patients and carers in the use and satisfaction with the intervention (data not shown).

\section{DISCUSSION}

The provision of a tailored education and support package to stroke patients and carers resulted in participants reporting a significantly higher self-efficacy for accessing stroke information, feelings of being informed and satisfaction with information received. The strengths of this study include: its randomised controlled design; an intervention whose design was informed by a series of previous studies with the intended population and the inclusion of both patients and carers, which enhances the applicability to health professionals working in this clinical area. It is noted that this combined analysis does not allow separation of patient and carer outcomes, which may be of interest to clinicians and researchers (please see online supplementary appendix D which details separate patient and carer scores at baseline and follow-up). Both patients and carers were recruited as participants for this study as the intervention was designed to meet the needs of both patients and carers and this also allowed maximisation of the power of the study.

A limitation of this study is that these results may not be generalisable to patients with more severe cognitive impairment or aphasia or to patients who require highlevel residential care and their carers. These populations are commonly excluded from studies of educational

Table 3 Satisfaction with intervention components

\begin{tabular}{lll}
\hline Intervention component & $\begin{array}{l}\text { Participant reported component } \\
\text { as useful } \mathbf{n}(\%)(\mathbf{n = 6 0 )}\end{array}$ & $\begin{array}{l}\text { Mean (SD) usefulness } \\
\text { rating (1-10) }\end{array}$ \\
\hline Written component & $53(88.3)$ & $9.1(1.4)$ \\
Talking to someone face-to-face (in hospital) & $58(96.7)$ & $8.9(1.6)$ \\
Talking to someone over the telephone (following discharge) & $45(75.0)$ & $7.9(2.3)$ \\
Having a telephone support person available if needed & $51(85.0)$ & $8.2(2.4)$ \\
\hline
\end{tabular}


interventions. Identifying effective educational resources for, and methods by which to conduct research into, these populations is a current research gap. Underpowering and the possibility of a type II error should also be considered. Finally, a 3-month follow-up period may also not have been sufficient to see the full influence of the intervention.

Our study used a 25-item stroke knowledge test which allowed comparison with the previous randomised controlled trial of the tailored written booklet used as part of the current study's intervention. ${ }^{16}$ Hoffmann et al ${ }^{16}$ found a non-significant between-group difference of 0.1 , while for this study it was 0.9 , yet also non-significant. A significant improvement in knowledge in the intervention group had been found by Lowe et al. ${ }^{15}$ The content of Lowe's booklets contained both general and patientspecific stroke information, while the content of our booklets was entirely tailored by the participant's choice of content and level of information. This more complete tailoring may make it difficult to accurately assess the knowledge of all participants using a uniform measure as not all participants will have been exposed to the same content. Use of a knowledge-outcome measure, that is, more sensitivity to differing content exposure or variations to the intervention (such as greater intensity) may be required to detect differences achieved from a tailored intervention.

Insufficient intensity of the intervention may have also contributed to the lack of significant differences between the groups for the other outcomes, along with an underpowering of the study. Although a total of up to six contacts with the health professional providing the intervention were offered, some participants declined some of these. This may have diluted the effect of the intervention. Possible explanations for the amount of postdischarge contact being considerably less than the amount of predischarge contact include: reduced tolerance for long-telephone conversations due to stroke-related or carer-related fatigue; difficulty in engaging some participants in discussion over the telephone or needs other than information taking a higher priority once a patient has left the acute ward. Additionally, although care was taken to ensure that the telephone contacts occurred at times suitable to the participant, the participants may have felt that they did not have 'time to talk' or were not as prepared for the discussion as they could have been. This emphasises the need to complete a regular, formal review of information needs. ${ }^{18} 35$ Formalising the information provision by scheduling an outpatient appointment may overcome some barriers of telephone communication, but may create other difficulties for patients and carers such as community mobility. The use of alternative communications such as computer-based videoconferencing may be more resource efficient and time efficient and more convenient for patients and/or carers who experience difficulties with community mobility and transport poststroke. Alternative solutions should be explored, depending on the resources and infrastructure available to stroke patients, their carers, and the health facility in which the health professionals work. Information needs persist and change beyond hospital discharge ${ }^{4} 36$ and health professionals need to find ways to continually meet these changing needs.

In the current study, participants in the intervention group had a significantly better self-efficacy for accessing stroke information. Several components of the intervention may have directly contributed to this, including: the written information booklet contained a detailed 'Where to get help' section, and the health professional providing the intervention modelled strategies which encouraged the use of support networks and explored barriers to accessing them and ways of overcome them. Several health-education theories describe self-efficacy as an important precursor to performance of a task. ${ }^{20}$ This has important implications for the abilities of patients with stroke and their carers to meet ongoing information needs, as it suggests that the intervention may empower them to independently access stroke information even after the cessation of the intervention period. Facilitating self-efficacy has been found to improve longer-term health outcomes in patients with chronic health conditions. ${ }^{37}$

In the current study, participants in the intervention group also demonstrated better satisfaction than control group participants. Higher satisfaction was also found by Hoffmann et al. ${ }^{16}$ The intervention group participants rated all four intervention components highly, including the postdischarge options of talking to someone over the telephone and having a telephone support person available if needed. A Cochrane review of a health professional-initiated telephone contact with patients following hospital discharge concluded that the effect of this medium on patient outcomes is currently inconclusive. ${ }^{38}$ While this review included studies which involved patients from various diagnostic groups, it did not include any studies specifically with stroke patients. The needs of stroke patients and their carers postdischarge differ quite substantially from those of other patient groups and stroke-specific studies evaluating this are needed. Stroke patients and carers have reported satisfaction with receiving telephone support when provided in combination with a face-to-face provision $^{39}$ and a desire to receive telephone support as a follow-up to face-to-face provision. ${ }^{40}$

The high ranking of the usefulness of having someone to call with questions was surprising, given that this option was utilised by only one participant. It may be that participants did not use this option because the health professional who provided the intervention appropriately elicited and addressed the information needs during the health professional-initiated contacts, or that the intervention group participants accessed other sources of information to ask additional questions. Nevertheless, it appears that participants in this study were satisfied to know that there was someone to call, 
even if they did not utilise the service. Whether this 'call in' component of the intervention would have been better utilised had the follow-up period been longer is also unknown. The need to provide contact details for any questions that may arise following discharge is acknowledged in national and international stroke care guidelines. $^{2} \quad 3 \quad 41$ Appropriate postdischarge support and/ or contact is often identified as a gap in services, by both patients and carers ${ }^{8}$ and hospitals which provide stroke care. ${ }^{42}$

Given the lack of effect on most of the outcome measures used in this study, it needs to be considered whether the improvement that was found in some outcomes is sufficient to justify the implementation of the intervention. Whether a stroke support service should continue to be funded if it does not address psychosocial outcomes has been raised in a previous study of stroke family support organisers. ${ }^{43}$ While the resources required to provide this intervention are less intensive than many of the other stroke patient and carer education and support interventions that have been trialled, a cost-effectiveness evaluation of this intervention, following refinement of some of its features, is required.

\section{Areas for future research}

A qualitative component of this study may have enhanced the interpretation of quantitative results and provided further insights into participants' perspectives about components of the intervention. Outcome measures relating to the self-efficacy, satisfaction and ratings of the importance of information and feeling informed were developed for this study because of the lack of existing measures and exploration of their psychometric properties and sensitivity to change, and their suitability for people with aphasia would be valuable.

Enhancement of the intervention may be needed to influence psychosocial outcomes. This enhancement may come from combining its provision with other active informational interventions. For example, hands-on practical training for carers has been demonstrated to reduce patient anxiety and depression and carer anxiety, depression and burden. ${ }^{44}$ A recent systematic review of educational needs of patients with stroke and their carers calls for improvements in stroke education. ${ }^{4}$ Enhancement and provision of this tailored stroke education and support package may be one way of addressing this need.

\section{CONCLUSION}

The provision of a tailored education and support package resulted in a significantly higher self-efficacy in accessing stroke information, feelings of being informed and satisfaction with information received of stroke patients and their carers. Refinement and enhancement of the package and subsequent evaluation of its effect are required before widespread implementation can be recommended.
Author affiliations

${ }^{1}$ Brighton Health Campus \& Services, Brighton, Queensland, Australia

${ }^{2}$ Centre for Research in Evidence-Based Practice, Faculty of Health Sciences and Medicine, Bond University, Gold Coast, Queensland, Australia and School of Health and Rehabilitation Sciences, The University of Queensland, St Lucia, Australia

${ }^{3}$ Communication Disability Centre and the CCRE in Aphasia Rehabilitation, School of Health and Rehabilitation Sciences, The University of Queensland, St Lucia, Queensland, Australia

${ }^{4}$ Neurology Department, Royal Brisbane and Women's Hospital, Brisbane, Queensland, Australia

Acknowledgements The authors would like to acknowledge Associate Professor Kryss McKenna for advice on project development and Dr Asad Khan for advice on statistical analysis.

Contributors SE was partially responsible for concept design, and primarily responsible for review of the literature, participant recruitment, data collection, data analysis and interpretation and manuscript preparation. TH and LW were partially responsible for concept design and also provided peer-review of data analysis and interpretation and manuscript preparation. SR and AW provided peer-review of data interpretation and manuscript preparation. All authors have read and approved the final manuscript.

Funding This research received no specific grant from any funding agency in the public, commercial or not-for-profit sectors.

Competing interests $\mathrm{TH}$ receives income from subscription fees to the tailored stroke education package, which enables technical maintenance of the website and database. At the time of the study, the lead author (SE) was in receipt of an Australian Post-Graduate Award scholarship, funding full-time $\mathrm{PhD}$ research at The University of Queensland. TH is supported by a National Health and Medical Research Council of Australia/Primary Health Care Research Evaluation and Development Career Development Fellowship (number: 1033038) with funding provided by the Australian Department of Health and Ageing.

Ethics approval The Royal Brisbane and Women's Hospital Human Research Ethics Committee; The University of Queensland's Behavioural and Social Sciences Ethical Review Committee and The Princess Alexandra Hospital Human Research Ethics Committee.

Provenance and peer review Not commissioned; externally peer reviewed.

Data sharing statement The dataset is available at Dryad repository (provisional doi:10.5061/dryad.4ms68), who will provide a permanent, citable and open access home for the dataset.

\section{REFERENCES}

1. National Stroke Foundation. Clinical guidelines for stroke management 2010. Melbourne: National Stroke Foundation, 2010.

2. Intercollegiate Stroke Working Party. National guidelines for stroke: Third Edition. London: Royal College of Physicians, 2008.

3. American Heart Association Council on Cardiovascular Nursing and the Stroke Council. Comprehensive overview of nursing and interdisciplinary rehabilitation care of the stroke patient: a scientific statement from the American Heart Association. Stroke 2010;41:2402-48.

4. Hafsteinsdóttir TB, Vergunst M, Lindeman E, et al. Educational needs of patients with a stroke and their caregivers: a systematic review of the literature. Patient Educ Couns 2011;85:14-25.

5. Murray J, Young J, Forster A, et al. Developing a primary care-based stroke model: the prevalence of longer-term problems experienced by patients and carers. Br J Gen Pract 2003:53:803-7.

6. Pound P, Gompertz P, Ebrahim S. Patients' satisfaction with stroke services. Clin Rehabil 1994;8:7-17.

7. O'Mahony PG, Rodgers $\mathrm{H}$, Thomson RG, et al. Satisfaction with information and advice received by stroke patients. Clin Rehabil 1997:11:68-72.

8. National Stroke Foundation. "Walk in our shoes": Stroke survivors and carers report on support after stroke. Melbourne: National Stroke Foundation, 2007

9. Hoffmann T, McKenna K. Analysis of stroke patients' and carers' reading ability and the content and design of written materials: 
recommendations for improving written stroke information. Patient Educ Couns 2006;60:286-93.

10. Wellwood I, Dennis MS, Warlow CP. Perceptions and knowledge among surviving patients with stroke and their carers. Age Ageing 1994;23:293-8.

11. Neufeld $P$. The adult learner in client-practitioner partnerships. In: McKenna KTooth L, eds. Client education: a partnership approach for health practitioners. Sydney: UNSW Press, 2006:57-87.

12. Bakas T, Austin JK, Okonkwo KF, et al. Needs, concerns, strategies, and advice of stroke caregivers the first 6 months after discharge. $J$ Neurosci Nurs 2002;34:242-51.

13. Tooth L, Refshauge K. The effectiveness of client education: a review of the evidence and future challenges. In: McKenna K, Tooth L. Client education: a partnership approach for health practitioners. Sydney: UNSW Press, 2006:22-56.

14. Pain H, McLellan D. The use of individualized booklets after a stroke. Clin Rehabil 1990;4:265-72.

15. Lowe D, Sharma A, Leathley M. The CareFile Project: a feasibility study to examine the effects of an individualised information booklet on patients after stroke. Age Ageing 2007;26:83-9.

16. Hoffmann T, McKenna K, Worrall L, et al. Randomised trial of a computer-generated tailored written education package for patients following stroke. Age Ageing 2007;36:280-6.

17. Forster A, Brown L, Smith J, et al. Information provision for stroke patients and their caregivers. Cochrane Database Syst Rev 2012;(11):CD001919.

18. Hoffmann T, McKenna K, Worrall L, et al. Evaluating current practice in the provision of written information to stroke patients and their carers. Int J Ther Rehabil 2004;11:303-10.

19. Eames S, Hoffmann T, Worrall L, et al. Delivery styles and formats for different stroke information topics: patient and carer preferences. Patient Educ Couns 2011;84:e18-23.

20. Sharma M, Romas JA. Theoretical foundations of health education and health promotion. Sudbury: Jones and Bartlett Publishers, 2008.

21. Sullivan KA, White KM, Young RM, et al. Predicting behaviour to reduce stroke risk in at-risk populations: the role of beliefs. Int $J$ Ther Rehabil 2009;16:488-96.

22. Knowles MS, Holton EF, Swanson RA. Andragogy in practice: expanding the usefulness of the andragogical model. The adult learner. 6th edn. Amsterdam: Elsevier/Butterworth Heinemann, 2005.

23. Hoffmann T, Worrall L, Eames $\mathrm{S}$, et al. Measuring outcomes in people who have had a stroke and their carers: can the telephone be used? Top Stroke Rehabil 2010;17:119-27.

24. Davis TC, Long SW, Jackson RH, et al. Rapid estimate of adult literacy in medicine: a shortened screening instrument. Fam Med 1993;25:391-5.

25. Eames S, Hoffmann T, McKenna K, et al. Community-based stroke information for clients with stroke and their carers: is there congruency between actual and recommended practice? Top Stroke Rehabil 2008;15:295-306.

26. Eames S, Hoffmann T, Worrall L, et al. Stroke patients' and carers' perception of barriers to accessing stroke information. Top Stroke Rehabil. 2010;17:69-78.
27. Hoffmann T, Russell T, McKenna K. Producing computer-generated tailored written information for stroke patients and their carers: system development and preliminary evaluation Int. J Med Inf 2004:73:751-8.

28. Hoffmann T. Development and evaluation of a computer-generated individualised written education package for patients following stroke and their carers (Unpublished doctoral thesis). Brisbane: School of Health and Rehabilitation Sciences, The University of Queensland, 2005.

29. Lorig K, Stewart A, Ritter P, et al. Outcome measures for health education and other health care interventions. Thousand Oaks: Sage Publications, Inc., 1996.

30. Zigmond AS, Snaith RP. The hospital anxiety and depression scale. Acta Psychiatr Scand 1983:67:361-70.

31. Hilari K, Lamping DL, Smith SC, et al. Psychometric properties of the Stroke and Aphasia Quality of Life Scale (SAQOL-39) in a generic stroke population. Clin Rehabil 06 2009;23:544-57.

32. Hilari K, Byng S, Lamping DL, et al. Stroke and Aphasia Quality of Life Scale-39 (SAQOL-39): evaluation of acceptability, reliability, and validity. Stroke 2003;34:1944-50.

33. Robinson B. Validation of Caregiver Strain Index. J Gerontol 1983;38:344-8.

34. van Exel NJA, op Reimer WJMS, Brouwer WBF, et al. Instruments for assessing the burden of informal caregiving for stroke patients in clinical practice: a comparison of CSI, CRA, SCQ and self-rated burden. Clin Rehabil 2004;18:203-14.

35. Mackenzie A, Perry L, Lockhart E, et al. Family carers of stroke survivors: needs, knowledge, satisfaction and competence in caring. Disabil Rehabil 2007;29:111-21.

36. Cameron JI, Gignac MAM. "Timing it right": a conceptual framework for addressing the support needs of family caregivers to stroke survivors from the hospital to the home. Patient Educ Couns 2008:70:305-14.

37. Lorig K, Ritter PL, Laurent DD, et al. Internet-based chronic disease self-management: a randomized trial. Med Care 2006;44:964-71.

38. Mistiaen P, Poot E. Telephone follow-up, initiated by a hospital-based health professional, for postdischarge problems in patients discharged from hospital to home. Cochrane Database Syst Rev 2006(4):CD004510.

39. Goldberg G, Segal M, Berk S, et al. Stroke transition after inpatient rehabilitation. Top Stroke Rehabil 1997:4:64-79.

40. Schure L, van den Heuvel E, Stewart R, et al. Beyond stroke: description and evaluation of an effective intervention to support family caregivers of stroke patients. Patient Educ Couns 2006;62:46-55.

41. National Stroke Foundation. Clinical guidelines for acute stroke management. Melbourne: National Stroke Foundation, 2007.

42. Hoffmann T, Cochrane T. What education do stroke patients receive in Australian hospitals? Patient Educ Couns 2009;77:187-91.

43. Lincoln NB, Francis VM, Lilley SA, et al. Evaluation if a stroke family organiser: a randomised control trial. Stroke 2003;34:116-21.

44. Kalra L, Evans A, Perez I, et al. Training carers of stroke patients: randomised controlled trial. Br Med J 2004;328:1099. 